\title{
Integrating WebCT Technology into the Practicum Experiences of Pre-Service EFL Teachers: Challenges and Rewards
}

\author{
Shu-hua $\mathrm{Wu}^{1} \&$ Sulaiman Alrabah ${ }^{1}$ \\ ${ }^{1}$ Language Center, College of Business Studies, Public Authority for Applied Education and Training, Kuwait \\ Correspondence: Shu-hua Wu, Language Center, College of Business Studies, Public Authority for Applied \\ Education and Training, Kuwait. E-mail: wu104ohio@yahoo.com.tw
}

Received: September 15, 2014 Accepted: September 25, $2014 \quad$ Online Published: September 26, 2014

doi:10.5430/ijelt.v2n1p13 URL: http://dx.doi.org/10.5430/ijelt.v2n1p13

\begin{abstract}
The present study investigated the impact of introducing WebCT technology as a course management tool in a practicum for pre-service teachers of English as a foreign language (EFL) in Taiwan. The study aimed to (1) describe the frequency and time duration of the web-browsing sessions that the students employed to access the different WebCT applications, and (2) explore the ways in which WebCT technology has contributed to the learning experiences of the participants. Data collection sources included students' web-browsing records, a student WebCT survey, interviews, and student reflective journals on the WebCT discussion board. Three software programs (Crystal Designer, Microsoft Excel and Ethnograph) were used to analyze the data of web-browsing patterns and to document the students' overall learning experiences through the use of the WebCT in the practicum course. After comparing the rates of the students' frequency of use and time duration on the WebCT to regular classroom attendance, the findings of the study indicated that the WebCT of the practicum was more compatible with the students' highly digitized lifestyles and learning preferences, and that the WebCT has also enhanced the students' learning experiences as indicated by the online survey instrument of the study.
\end{abstract}

Keywords: WebCT, foreign language teacher education, practicum, e-learning, computer-meditated instruction (CMI), web-based instruction

\section{Introduction}

Despite the great potential of WebCT technology for improving the teaching-learning environment, the most challenging aspects of using WebCT are the lack of information among teachers about this relatively-new technology, its impact on student learning of course content and objectives, and the types of solutions it can provide to many of the logistical and management challenges currently faced by the traditional low-tech formats of their courses (Rowley \& O'Dea, 2009; Sanchez, Hueros, \& Ordaz, 2013). In order to improve student learning experiences through computer technology, courseware designers and language teachers need to pay closer attention than has been devoted so far to the issue of how WebCT can be integrated within the curriculum. There is also a need to explore the patterns in which the course participants access the WebCT and to understand the relationships between these web-browsing patterns and the participants' attainment of course objectives. In other words, with the introduction of WebCT technology as an integral part of the curriculum for the purpose of achieving pre-specified educational objectives, there is a need to understand its potential in overcoming the logistical and management constraints posed by the traditional format of courses, and to explore both its drawbacks and benefits on those students who embrace the new technology as well as those who shy away from using it to its full potential.

More and more teachers are faced everyday with the integration of new WebCT technologies into their curriculums. However, current research does not address very well the needs of teachers new to a computer teaching environment (Weaver, Spratt, \& Nair, 2008). Such research can lead to more information being provided to teachers about a considerable range of technology-based solutions to challenges and constraints currently associated with the traditional low-tech format of courses now being offered to students world-wide. For example, while a traditional classroom needs physical space to have class, a computer-based class can practically meet any day, anytime, or anywhere. Needless to say that an increased understanding of new hi-tech solutions by teachers will impact the management and delivery of their courses so much so that the media employed in the teaching-learning process will 
be noticeably changed. This information can come about through closely-focused investigations of a wide range of relevant issues such as the interaction between web-based technologies and the curriculum, as well as the nature of the work of language teachers and teacher educators who have embraced the new computer-based technologies and introduced them into their courses. Moreover, the incorporation of WebCT technology into the design and implementation of courses is a promising research area. WebCT not only offers a potentially-rich environment for data collection because of the computer's ability to store in its memory large amounts of information related to different users' patterns of web-browsing, but also invites new investigations related to the outcomes of participating in WebCT courses especially on the kinds of learning experiences students may have (Takayoshi \& Huot, 2003).

\section{Purpose of the Study}

The purpose of this study was to investigate the interaction between WebCT technology and the practicum course. The introduction of WebCT technology within the design of the practicum course may entail changes in the ways in which the course is taught and delivered to the student teachers. The main motivations behind the current study were, therefore, the need to understand the consequences of integrating WebCT technology into the practicum course, and the role of WebCT in shaping the learning environment of the practicum course. The study aimed to provide answers for the following research questions:

(1) What were the web-browsing patterns in which the student teachers accessed the WebCT applications of the practicum course in terms of frequency and time spent online?

(2) How did the participants assess their overall learning experiences within the WebCT environment of the practicum course?

\section{Review of the Literature}

Many researchers (e.g., Liu, 2001; van Olphen, 2007) suggested that the introduction of WebCT technology within the practicum course as a management tool can offer a range of solutions to many of the logistical and management challenges that have been identified within the field of language teaching to hamper the successful implementation of the practicum course in its present "traditional" format. This review discusses the ways in which WebCT solutions may address some of the challenges that have been traditionally associated with the practicum course. In order to understand the ubiquitous role of technology in teaching practices, the review is divided into three sections which discuss (1) integrating web-based technology into the curriculum, (2) technology-based solutions to traditional challenges, and (3) the role of the WebCT technology in promoting the quality of student learning experiences while taking the practicum course.

\subsection{Integrating Web-Based Technology into the Curriculum}

The integration of web-based computer technology into the curriculum represents a major concern for teachers approaching teaching with computers for the first time. The literature abounds with articles that continue to raise important issues such as the need for the teacher's pedagogical theories to inform the shape web-based technology takes in his/her curriculum, the ways in which contemporary learning theories (e.g., Constructivism) are supported or not supported by web-based technology, and introductions to the language and concerns involved in teaching specific topics such as writing and reading with web-based technologies (Butler-Pascoe \& Wiburg, 2003; Kern \& Warschauer, 2000). Although these issues remain important for an instructor using web-based technologies in 2013, the scholarship produced five or six years ago is not as relevant as it might have been when it was first published. The specific technologies have evolved and the software discussed in such publications is quite different from that loaded on the hard drives of the computers that teachers and students will be using. Kern, Ware, and Warschauer (2008) further suggested that "the growing complexity of discussions involved in network-based language teaching (NBLT) highlights the importance of technology integration in both preservice and inservice teacher education" (p. 290).

Computer technology develops very rapidly. According to Takayoshi and Huot (2003), "An industry standard seems to be that a newly-purchased computer will be obsolete in three years since technological developments (i.e., programs, web applications, and peripherals) will require newer machines to support them" (p. 2). Moreover, technologies not available ten or twenty years ago are now quite commonplace (e.g., smart phones). So, although early scholarship on using computers for teaching is certainly relevant in terms of its larger claims, it is no longer current in terms of the existing technological and theoretical realities of many classrooms. As college and university teachers are increasingly being called upon to teach with web-based technologies, the need for research on how best 
to teach with computers is becoming more urgent.

\subsection{Technology-Based Solutions to Traditional Challenges}

The field of language teaching has identified a number of logistical and management challenges that have always undermined the practicum experience in its present "traditional" format. These logistical and management challenges include the issue of easy accessibility between the teacher educator and the student teachers participating in the practicum, the physical constraints placed on teacher educators in conducting lesson/classroom observations of individual student teachers, the difficulty faced by teacher educators in properly monitoring the professional development of student teachers, and the data collection problems involved in conducting research on the participation patterns of the student teachers in the practicum course. Depending on the different contexts and situations in which the English practicum course is being applied in many parts of the world, it is safe to assume that the full integration of WebCT technology within the practicum course will influence in many tangible ways the practicum course learning and teaching experiences for both student teachers and teacher educators.

Although the practicum course serves a central role in teacher development, its successful management has always been faced with several logistical challenges that may complicate a teacher educator's or a researcher's task. As a result of the WebCT design of the practicum course, teacher educators find themselves in a better position to efficiently manage and steer the overall direction of the course due to the communication of changes and announcement that relate to either individual students or to the practicum class as a whole. For example, accessibility between teacher educators and student teachers has been difficult because of the inability of the teacher educator to observe and adequately manage large numbers of student teachers within the practicum course (Breen, et al., 2001). The introduction of WebCT design as a course management tool for the practicum course is a new way to address these logistical challenges that have always faced the practicum course in teacher development programs. For example, one way in which computers promote interaction between teacher educators and student-teachers is by creating a bulletin board in which announcements are made and changes to schedules are approved by the teacher educator ahead of time. The WebCT can, therefore, provide much better access between teacher educators and student teachers than the traditional practicum course. Bulletin boards in which learners and teachers can post messages to be read later by others are built into a WebCT environment; users can post messages and comments on the original posting. Beatty (2010) suggested that the advantage of bulletin boards over e-mail is that the messages are shared with a broader community in which readers have more time to consider their comments. Moreover, access is facilitated through WebCT technology on a continuous basis and is also available round the clock through both synchronous and asynchronous communication. Chen and Zhao (1997) reported on a study which used synchronous communication: a web-based chat line software program that allows learners to communicate in real time, or, rather, as fast as they can type. One of the advantages of such computer-mediated communication (CMC) is that transcripts of such sessions can be made available to the teacher/researcher for analysis. But in the case of a practicum course, in addition to using the transcripts for the purpose of data analysis, the transcripts of the chat sessions can be used by the students for feedback on classroom teaching on their own as well as on their peers' performances, and also on discussions on theoretical, empirical, and pedagogical issues and concerns (Melville, Bowen, \& Passmore, 2011).

Another challenge facing the traditional format of the practicum course for which the integration of WebCT technology can provide a solution is the difficulty of physically observing individual student teacher performances, especially in large classes. This situation often results in a lack of observation time of the student teaching performance which reduces the chance of interaction and co-operation between the teacher educator and the students. By providing students with a space on which to display their pre-recorded VCDs of teaching performances, the WebCT can provide a platform for collaboration and co-operation. In a study conducted by Van Handle and Corl (1998), e-mail was used to create a pen pal situation between students studying German at two American universities. The e-mail pen pal club is an asynchronous communication technology in which messages were sent like letters and replies received at an undetermined later time. In effect, by creating an asynchronous communication environment in which the students have a platform to display and observe web-based VCD recordings of students' classroom teaching performances, the number of observers is exponentially increased because the whole class is able to monitor online students' teaching performance and send feedback later on the online observation instrument. Another benefit, therefore, of introducing the WebCT within the practicum course as a form of asynchronous communication is that the feedback each student receives on his/her performance is increased several fold. Within a traditional practicum context, only feedback from the teacher educator is provided with few chances of receiving peer comments on students' teaching performance. Finally, researching the practicum course experience is much more accessible because of the chance to monitor students' browsing patterns of the WebCT of the practicum course. These patterns can provide reliable indicators of the frequency of student involvement in learning from the practicum course tool. 


\subsection{Enhancing the Quality of the Practicum}

A further challenge facing the practicum course in its traditional format is the difficulty of monitoring student teachers' growth as teachers in terms of the conceptualization of the teaching act (e.g., Richards \& Lockhart, 1994). Student teachers' entries and reflective notes on their own and others' teaching performances, which are accommodated by the WebCT design of the practicum course, may provide researchers with clues about student teachers' growth as teachers as well as of their reflections on the effects of their teaching on their own students. Brown (1995) argued that through observing experienced teachers, novice teachers can develop a repertoire of strategies and techniques which they can apply in their own teaching. However, in using classroom observation in language teacher education programs, it is necessary to go beyond a focus on techniques and strategies experienced teachers employ, and to use observation as a way of collecting information to develop a deeper understanding of teachers as reflective practitioners.

Incorporated at the center of the online observation instrument, WebCT technology may become a platform to collect data from student feedback on VCD recordings of student performance as well as a site for reflection upon receiving teacher and peer feedback to be entered by each student at the end of each observation. Based on Brown's (1995) observation instrument, teacher development may be classified under one or more of the following categories: (1) conducting class while maintaining a good tempo and pace of lessons, (2) applying effective teaching strategies, (3) classroom management techniques, (4) using audio-visual aids, (5) promoting learner participation, and (6) mastery of conversational and written English while teaching. As an outcome of the introduction of WebCT technology as a management system for the practicum course, an important question is thus related to the ways in which the WebCT platform can impact the learning experiences of the participating students.

There was a need, therefore, for a study to investigate the interaction between WebCT technology and the practicum course. The purpose of this study was to analyze the patterns of web-browsing by the student teachers in terms of frequency and duration, and to describe the impact of WebCT technology on the quality of the WebCT practicum course as reflected on their responses to an online survey instruments on their overall learning experiences.

\section{Methodology}

The research methods employed in this study utilized the computer as a main source of data collection and analysis to investigate the students' web-browsing patterns and overall learning experiences through the use of the WebCT in a practicum course. Another source of data was the students' reflective journal entries as well as interviews between the researchers and the students. The analysis of reflective journals and interview data were further used as a triangulation to confirm/disconfirm the findings of the study. The following sections describe in further detail the methods of data collection and data analysis used in this study.

\subsection{Data Collection}

Data collection methods included (1) weekly web-browsing records by the pre-service EFL teachers on the WebCT of the practicum course, (2) online reflective journals posted on the discussion board related to students' teaching performances and feedback on an online observation instrument, (3) an online WebCT survey, and (4) interviews on the overall learning experiences through the use of the WebCT in a practicum course. The study was conducted over a period of six months. The study sample included an intact class of 35 subjects who were taking a practicum course at the English department of a university in Taiwan. In order to provide theoretical support for their practical teaching experiences, the students were required to attend a weekly two-hour class on campus to discuss teaching methods and provide opportunities for micro-teaching. The WebCT platform of the practicum was used for communication between the teacher and students about the topics that were introduced in the regular class, as well as feedback on the recorded performances of the 35 students. A weekly VCD recording of one student's teaching performance was displayed on the WebCT so that the rest of the students evaluated it and gave their feedback on the online observation instrument of the WebCT. The computer was, therefore, used as a main data collection source for the web-browsing patterns employed by the student teachers. Without informing the students so as not to bias their access and duration patterns, the computer was programmed to keep a record detailing the times and the duration in which any of the participants entered the WebCT. The database of the study was automatically updated by the WebCT every time a student made an entry or observed an online VCD lesson performed by another student teacher. By the end of the data collection stage, the computer was used to provide a detailed record of each student's web-browsing behavior as well as the totality of computer-mediated communication by the whole class. 


\subsection{Data Analysis}

Data analysis was devoted to finding answers for the two research questions of the study which focused on the students' web-browsing patterns and their overall learning experiences through the use of WebCT in the practicum course. Data analysis methods of web-browsing records and survey data included counting the frequency and time duration of web-browsing patterns and categorizing students' overall learning experiences on the WebCT of the practicum course. Interview data and reflective journals were analyzed to verify and triangulate the findings of the study. The researchers mainly relied on the computer to analyze the data to answer the two research questions. The process was facilitated through the use of three software programs to analyze different sets of data. First, after getting each individual student's total online data records from the WebCT, the software program Crystal Designer analyzed the students' web-browsing patterns in terms of frequency of use and time duration. Second, Microsoft Excel analyzed the WebCT survey on the ways the WebCT contributed to their overall learning experiences in the practicum course. Third, Ethnograph was used to analyze the students' reflective journals which they posted on the WebCT, as well as the interviews between the researchers and the students about the students' learning experiences on the WebCT of the practicum course.

\section{Findings and Discussion}

The findings and discussion are organized around three separate tables that describe the different aspects of the data that were analyzed to investigate the students' access patterns and their overall learning experiences. After the relevant figures are presented in the discussion, the researchers made sense of the data by referring to the factors that have contributed to the students' web-browsing patterns and the role of the WebCT in the students' learning experiences.

\subsection{Web-browsing Patterns}

The first research question was focused on the web-browsing patterns in which the student teachers accessed the WebCT applications of the practicum course in terms of frequency and time spent online. Data analysis was conducted on the computer-generated data of student web-browsing behaviors for the purposes of sorting, grouping, categorizing, and interpreting online browsing patterns. Means and standard deviations were used to seek the overall online browsing patterns in the WebCT.

Table 1. WebCT online browsing patterns

\begin{tabular}{lccc}
\hline & Number of Students & Percentage (\%) & Rank \\
\hline (1) $\quad$ Number of Sessions & 2 & 5.71 & \\
\hline $50-100$ times & 15 & 42.86 & 1 \\
$100-150$ times & 10 & 28.57 & 2 \\
$150-200$ times & 1 & 2.86 & 5 \\
200-250 times & 7 & 20.00 & 3 \\
$\quad$ More than 250 & & & \\
(2) Duration of Sessions & 12 & 34.29 & 2 \\
Less than 48 hours & 15 & 42.86 & 1 \\
48-72 hours & 5 & 14.29 & 3 \\
72-96 hours & 3 & 8.57 & 4 \\
$\quad$ More than 96 hours & & & \\
\hline
\end{tabular}

These data were displayed in table 1 which depicted the totality of the students' online browsing behavior $(\mathrm{N}=35)$. Information was provided about student access to the WebCT in terms of (1) the number of sessions in 5 equal intervals from 50 to more than 250 sessions, and (2) the duration of sessions in 4 equal intervals ranging from less than 48 hours to more than 96 hours of browsing time on the WebCT. Regarding the number of sessions in which the 35 students accessed the WebCT, there was considerable variation between two groups at both ends of the continuum. The first group ranged from 50-100 sessions (only 2 students or 5.71\%) to 200-more than 250 sessions ( 8 students or $22.86 \%$ ) over the period of six months of the study. The second group included twenty five students (or $71.43 \%$ of 
the whole class) who accessed the WebCT between more than a 100 to less than 200 times throughout the entire period of the study. It is also important to note that even though the class met for 24 class periods, the majority of students ( 33 out of a total of 35 students or $94.29 \%$.) accessed the WebCT at least 100 times. In other words, the ratio is 4 to 1 for each one class period the students got online for 4 times. Even though the class met for a total of 24 class periods, most students ( 25 out of 35 or $71.43 \%$ ) got online 100-200 times. There were seven students who got online more than 250 times with $20 \%$ while there were only two students (or $5.71 \%$ ) who got online less than 100 times.

Regarding the duration of sessions on the WebCT, the students had 24 class periods over the period of six months. A large percentage of the students (23 students out of 35 students $65.72 \%$ ) got online for more than 48 hours. In other words, the ratio of class periods to the duration of sessions for the students was 1 to 2, or one class period to 2 hours of browsing online. Some students ( 5 out of 35 students or 14.29\%) got online for 72 to 96 hours. Some others ( 3 out of 35 hours) got online more than 96 hours (or $8.57 \%$ ) while there were 12 students or $34.29 \%$ who got online for less than 48 hours.

The evidence contained in Table 1 suggested the students utilized the WebCT of the course much more than the regular weekly class session which was devoted to provide theoretical support for the practicum course. Several factors could have contributed to the disproportionate differences between the regular class and the WebCT in terms of frequency and duration. But the two most likely factors are (1) the full integration of the WebCT platform within the practicum, and (2) the compatibility of the WebCT with the digitized lifestyles and learning preferences of most of the students who participated in the study. First, the WebCT platform was fully integrated within the curriculum of the practicum course. Weekly class discussion topics were conducted to promote the objectives of the practicum course. After the weekly topics were introduced during the class periods, the students accessed the WebCT both to see the related PowerPoint presentations on the same topics, and to exchange further questions and views with other classmates and the teacher on related points that were not necessarily covered in the class lecture or the PowerPoint presentations. Moreover, the WebCT was used to access all the video recordings of the weekly teaching performances for the whole class. This arrangement provided the students with the opportunity to observe and to provide peer feedback to those students who gave the performances. The fact that the WebCT became a podium for all of these exchanges made it almost impossible for any student to participate in the course without having regular and repeated access to the WebCT of the course. On the contrary, the students were motivated to access the WebCT to keep abreast of any new announcements or class assignments which were regularly placed by the teacher on the bulletin board of the WebCT. The integration of the WebCT within the design of the curriculum of the practicum could, therefore, partly explain the disproportionate differences between regular class attendance and students' regular and repeated access to the WebCT.

The second factor related to the disproportionate differences between the traditional class and the WebCT in terms of frequency and duration was due to the compatibility of the WebCT with the students' digitized lifestyles and learning preferences. Kern, Ware, and Warschauer (2008) stated that "the first generation of digital natives who have grown up using the Internet and view it as an entirely ordinary environment of interaction is now entering higher education" (pp. 289-290) (italics theirs). The students who participated in the study reported in their interviews and journal reflections that they found the WebCT platform more fitting to their lifestyles than the regular class period on campus. They could access the WebCT anytime, anywhere, and for as long as they wanted. The computer tracked students' participation in the online material, including the number of minutes spent using the course materials and the times during which the students accessed the WebCT. Data provided by Crystal Designer showed that many of the students accessed the WebCT of the course during the evening hours and they stayed online until very late into the night. The students also reported that they liked the variety of applications on the WebCT and the flexibility with which they could use them either individually, as a whole class, or in groups to discuss specific topics or provide peer feedback on a single student performance by using the available applications of the WebCT, such as the online observation instrument. The WebCT provided password protection so that only the students who were enrolled in the practicum course had access to the materials and applications of the practicum as well as each other's writing, questions, and journal entries. Such an arrangement also meant that, once a student was immersed in the WebCT environment, she/he was more likely to focus on communicating with classmates and the teacher. The familiarity of the participants on the WebCT was much more re-assuring to the students than surfing the net and browsing the web to communicate with the world at large.

\subsection{The WebCT and Student Learning Experiences}

The second research question was focused on the participants' assessment of their overall learning experiences within the WebCT environment of the practicum course. The researchers used an online WebCT Student Survey as a 
data elicitation instrument to obtain answers about the ways in which the students assessed their overall experiences. The analysis focused on (1) the general background information and the overall reactions to the use of the WebCT within the practicum course, and (2) more specific information related to student ratings of each of the applications of the WebCT including the online classroom observation instrument and details of how the WebCT supported their learning experiences.

Table 2. Background information and overall experience of WebCT

\begin{tabular}{lll}
\hline & Mean & SD \\
\hline (1) Background Information & & \\
Years of exposure to computers & 4.31 & 0.80 \\
How WebCT was used in class & 2.89 & 1.02 \\
Previous WebCT experience & 3.14 & 0.43 \\
$\quad$ Location of access to WebCT & 3.54 & 1.04 \\
(2) Overall Experience of WebCT & & \\
Course material learning & 4.06 & 0.34 \\
Incorporate WebCT into course design & 3.54 & 0.70 \\
Positive attitude toward using WebCT in the future & 3.54 & 0.78 \\
\hline
\end{tabular}

The first part of Table 2 was devoted to the students' background information and their opinions about the points of access to the WebCT of the practicum course. The survey data showed that most of the students had 3 to 4 years of computer experience prior to taking this course $(\mathrm{M}=4.31 \mathrm{SD}=0.80)$. The data also indicated that most of the students had previously used WebCT in other classes $(M=3.14 \mathrm{SD}=0.43)$. Some of the students had experiences in which a WebCT was used as a supplement to regular class instruction, and some others had online classes in which a WebCT was the only medium of instruction $(\mathrm{M}=2.89 \mathrm{SD}=1.02)$. The fact that most of the students who participated in the study have previously experienced using WebCT in other courses meant that they were not totally unfamiliar with the technology. The advantage for them was that they had less to learn about how to use WebCT and more time spent on the task of learning the course materials of the practicum. Beatty (2010) suggested that students who learn WebCT in one course can transfer that learning to another course. Another fact learned from the survey that might have contributed to the ease with which the students took to the WebCT of the practicum course was the convenience of finding several points of access to the WebCT. Some students reported that they used the WebCT at home and some others reported that they accessed the WebCT by using the conveniently-located, campus-wide computer labs of the university $(\mathrm{M}=3.54 \mathrm{SD}=1.04)$. Easy access to course materials made a big difference for the students when it came to deadlines and due work, especially when we take into account that they lived on the residence halls of the university and that practically none of them owned a car. In sum, the background information and points of access data found in the first part of Table 1 can be explained with reference to the compatibility of the WebCT with the students' digitized lifestyles and learning preferences. This factor has been previously cited in the earlier analysis to account for the disproportionate differences between regular class attendance and the frequency and duration of student access to the WebCT of the practicum course.

The second part of Table 2 was devoted to the students' overall reactions to using the WebCT of the practicum course. The students mostly agreed with the statement that the WebCT helped them learn the course material $(\mathrm{M}=4.06$ $\mathrm{SD}=0.34)$. The students also mostly agreed with the statement that they want the WebCT to be part of the course if they retake it in the future $(\mathrm{M}=3.54 \mathrm{SD}=0.70)$. They mostly agreed with the statement that they will feel comfortable taking another course that used WebCT $(\mathrm{M}=3.54 \mathrm{SD}=0.78)$. These figures are consistent with a fact that the WebCT platform was fully integrated within the curriculum of the practicum course. In fact, the two most important objectives of the practicum course were that the students will recognize that the WebCT helped them learn the material of the course, and that they will feel confident to take another WebCT course in the future. 
Table 3. Specifics of learning experiences using WebCT

\begin{tabular}{lll}
\hline & Mean & SD \\
\hline (1) Ratings of Each Application & 3.80 & 0.58 \\
Viewing documents & 3.43 & 0.98 \\
Navigating & 3.71 & 0.67 \\
Downloading & 3.86 & 0.55 \\
Uploading & 3.77 & 0.60 \\
Participating in discussions & 3.40 & 1.09 \\
Printing materials from WebCT & 3.31 & 0.96 \\
Using electronic reading & & \\
(2) Evaluating Classroom Observation Experience & 3.57 & 0.74 \\
Viewing VCDs easily and efficiently & 3.74 & 0.51 \\
Filling out the observation form & 3.54 & 0.78 \\
Enhancing subject matter knowledge & 3.60 & 0.60 \\
Enhancing pedagogical content knowledge & 3.63 & 0.60 \\
Enhancing classroom management skills & & \\
(3) Details of how WebCT Supported Learning & 3.91 & 0.70 \\
Reviewing class discussion through PowerPoint notes & 3.83 & 0.66 \\
Easy access to peers' actual teaching & 3.83 & 0.62 \\
Reflective discussion sections on the web & & \\
\hline
\end{tabular}

Table 3 indicated the students' reactions to the ease or difficulty of specific learning experiences while using the WebCT. Part 1 of the table was devoted to the applications the students used that together illustrate the breadth of what was available to them on the WebCT. Part 2 contained items about the online observation instrument, and part 3 was focused on the specific details of how the WebCT supported student learning. In part 1 of Table 3, most of the students rated the use of the applications in the WebCT as easy, such as viewing documents $(\mathrm{M}=3.80 \mathrm{SD}=0.58)$, navigating ( $\mathrm{M}=3.43 \mathrm{SD}=0.98)$, downloading $(\mathrm{M}=3.71 \mathrm{SD}=0.67)$, uploading $(\mathrm{M}=3.86 \mathrm{SD}=0.55)$, participating in discussion $(\mathrm{M}=3.77 \mathrm{SD}=0.60)$, printing materials from WebCT $(\mathrm{M}=3.40 \mathrm{SD}=1.09)$, and using electronic reading $(\mathrm{M}=3.31 \mathrm{SD}=0.96)$. Moreover, part 2 of Table 3 indicated that most students' responses to the online classroom observation instrument were positive in terms of viewing VCDs easily and efficiently ( $M=3.57 \mathrm{SD}=0.74)$, filling out the items of the observation instrument $(\mathrm{M}=3.74 \mathrm{SD}=0.51)$, and as a result of having participated in the observations, enhancing their own subject matter knowledge $(\mathrm{M}=3.54 \mathrm{SD}=0.78)$, enhancing their own pedagogical content knowledge $(\mathrm{M}=3.60 \mathrm{SD}=0.60)$, and enhancing their own classroom management skills $(\mathrm{M}=3.63, \mathrm{SD}=0.60)$. Finally, part 3 of Table 3 indicated that most students agreed that using WebCT supported their learning of course materials because they could review class discussions through the PowerPoint presentations on the WebCT $(\mathrm{M}=3.91 \mathrm{SD}=0.70)$. Most students agreed also that the WebCT provided them with easy access to their peers' videotaped teaching performances $(\mathrm{M}=3.83 \mathrm{SD}=0.66)$, and that the reflective journal sections on the web were beneficial to their growth as English language teachers $(\mathrm{M}=3.83 \mathrm{SD}=0.62)$.

With regard to the statistics on both tables 2 and 3, the general conclusion that can be drawn as an answer to the second research question is that the WebCT enhanced the overall learning experiences of most of the students of the practicum course. Specifically, the WebCT was not only fully integrated within the practicum course, but it was also compatible with the students' digitized lifestyles and learning preferences. This helped the WebCT create an environment which facilitated optimal learning conditions. The applications of the WebCT were deemed easy to use by the students. These included viewing documents, navigating, downloading, uploading, and participating in discussions, printing materials, and electronic readings. The online observation instrument was considered helpful for most of the students in viewing the VCDs of student performances, filling out the observation instrument, and enhancing their subject matter knowledge, their pedagogical content knowledge, and their classroom management 
skills. Finally, the students responded positively to detailed questions about their learning experiences on the WebCT which included using the PowerPoint presentations to understand course content, the ability to easily access their peers' videotaped teaching performances, and the value of their reflective journals in promoting their growth as English language teachers.

\section{Conclusions}

There are two conclusions that can be drawn from this study. First, in terms of the frequency of access to the WebCT of the practicum course, the students as a group accessed the WebCT at least four times more frequently than regular class attendance. In terms of the duration of sessions in which students accessed the WebCT, the majority of the students stayed online for two to three times more than their attendance in the regular class of the practicum. Second, the WebCT contributed in several positive ways to the overall learning experiences of most of the practicum course students. The statistics about the disproportionate differences between the frequency and duration of the students' access to the WebCT in comparison to the regular class attendance and the students' overall learning experiences from the WebCT were accounted for by reference to two factors: (a) the full integration of WebCT within the practicum course, and (b) the compatibility of the WebCT with most of the students' digitized lifestyles and learning preferences.

\section{Implications for Pedagogy and Research}

The implications drawn from this study apply to pedagogy as well as future research. Unlike courses in which computer technology is an add-on supplement to the already existing course syllabus, the WebCT in this study was fully-integrated within the curriculum of the practicum course. The integration of WebCT technology within the course curriculum is a model that can be generalized to other content courses in the English department such as Second Language Acquisition, Language Testing, and of course Computer-Assisted Language Learning. Normally in a college situation, a teacher would incorporate computer technology to encourage students to look for articles and materials on the Web, or to reinforce course content by logging on to sites which offer students practice and exercises on specific skills introduced in class. This situation makes computer technology an extra option available to students or an add-on component to the main course content. But in this study, students could not effectively partake in course activities without repeated and regular access to the WebCT of the practicum course. So in this case, computer technology is much more than an optional add-on component to the course curriculum. This is a model that seems to be working in terms of enhancing the learning experiences of the students and, in effect, promoting the main objectives of the course. Once the model has been applied, there is a need for further research to be conducted to empirically and independently investigate the interaction between the WebCT and the degree of integration within the curriculum of these courses. Finally, there is a need to conduct further research on student populations who have never had the WebCT experience previously to see the extent to which lack of familiarity with this technology may impact its potential benefits on the learning experiences of these populations.

\section{References}

Beatty, K. (2010). Teaching \& researching: Computer-assisted language learning (2nd ed.). New York: Rutledge.

Breen, M., Hird, B., Milton, M., Oliver, R., \& Thwaite, A. (2001). Making sense of language teaching: Teachers' principles and classroom practices. Applied Linguistics, 22(4), 470-501.

Brown, J. D. (1998). The elements of language curriculum: A systematic approach to program development. Boston: Heinle \& Heinle.

Butler-Pascoe, M. L., \& Wiburg, K. M. (2003). Technology and teaching English language learners. Boston: Allyn and Bacon.

Chen, D., \& Zhao, Y. (1997). EWeb and homepage maker: Making it easier to develop content on the WWW. Computer Assisted Language Learning, 10(5), 427-441. http://dx.doi.org/ 10.1080/ 0958822970100503

Kern, R., Ware, P., \& Warschauer (2008). Network-based language teaching. In N. Van Deusen-Scholl, \& N. H. Hornberger (Eds.), Encyclopedia of language and education: Second and foreign language education (2nd ed.) (Vol. 4, pp. 281-292). New York: Springer. 
Kern, R., \& Warschauer, M. (2000). Introduction: Theory and practice of network-based language teaching. In M. Warschauer, \& R. Kern (Eds.), Network-based language teaching: Concepts and practice (pp. 1-19). New York: Cambridge University Press.

Liu, H. C. (2001). Incorporating computers into English classrooms: Curriculum design issues. Selected papers from the Tenth International Symposium on English Teaching, Taipei, November 16-18.

Melville, W., Bowen, M. G., \& Passmore, G. (2011). Pre-service teacher reflections, video-conference and WebCT: An exploratory case study. Electronic Journal of Research in Educational Psychology, 9(2), 799-822.

Richards, J., \& Lockhart, C. (1994). Reflective teaching and second language classrooms. New York: Cambridge University Press.

Rowley, J., \& O'Dea, J. (2009). How do students perceive the enhancement of their own learning? A comparison of two Education faculties' experiences in building an online learning community for bachelor of Music Education and Bachelor of Education students. Proceedings of the annual conference of the Australian Teacher Education Association (ATEA), Albury, 28 June-1 July. http://atea.edu.au/ ConfPapers/2009/Refereed/Rowley.pdf

Sanchez, R., A., Hueros, A. D., \& Ordaz, M. G. (2013). E-learning and the University of Huelva: A study of WebCT and the technological acceptance model. Campus-Wide Information System, 30(2), 135-160.

Takayoshi, P., \& Huot, B. (2003). Teaching writing with computers: An introduction. Boston: Houghton Mifflin Company.

Van Handle, D. C., \& Corl, K. A. (1998). Expanding the dialogue: Using electronic mail and the Internet to promote conversation and writing in intermediate German language courses. CALICO Journal, 15(3), 129-143. http://dx.doi.org/10.11139/cj.15.1-3.129-143

van Olphen, M. (2007). Perspectives of foreign language preservice teachers on the use of a web-based instructional environment in a methods course. CALICO Journal, 25(1), 91-109. http://dx.doi.org/10.11139/cj.25.1.91-109

Weaver, D., Spratt, C., \& Nair, C. S. (2008). Academic and student use of a learning management system: Implications for quality. Australasian Journal of Educational Technology, 24(1), 30-41. http://www.ascilite.org.au/ajet/ajet24/weaver.html 